\title{
Falhas de Estruturas de Aço Soldadas Devido a Reduzida Ductilidade
}

\author{
(Failures of Welded Steel Structures Due to Reduced Ductility)
}

\author{
Ivan Guerra Machado \\ Universidade Federal do Rio Grande do Sul, PPGE3M, Laboratório de Soldagem \& Técnicas Conexas \\ Porto Alegre, RS,Brasil,welder@ufrgs.br
}

\begin{abstract}
Resumo
O principal propósito deste artigo é demonstrar para os (as) engenheiros(as) projetistas e de soldagem, que numa estrutura de aço estrutural soldada a ductilidade possui importância equivalente ou ainda maior do que a resistência e a rigidez. Porém, o elevado nível requerido para a ductilidade não pode ser somente dos metais base e de solda. A análise tem que ser abrangente, envolvendo todos os componentes e também a estrutura completa.
\end{abstract}

Palavras-chave: Soldagem. Projeto e Ductilidade de Estruturas Soldadas. Propriedades Mecânicas e Metalúrgicas.

\begin{abstract}
The main purpose of this paper is to show for the designers and welding engineers, that in a welded structural steel structure ductility has equivalent or even bigger importance than strength or stiffness. However, the required high level for ductility cannot be only for base and weld metals. The analysis must be comprehensive, involving all components and also the whole structure.
\end{abstract}

Key-words: Welding. Design and Ductility of Welded Structures. Mechanical and Metallurgical Properties.

\section{Introdução}

Entre os propósitos deste trabalho está salientarmos principalmente para os engenheiros projetistas e de soldagem-, a importância da ductilidade sobre falhas em estruturas de aço soldadas devido a projetos que redundam em excessiva rigidez e enfatizar que as conexões são parte integral da análise estrutural. Adicionalmente, mas não de menor importância, temos verificado que alguns engenheiros projetistas insistem em considerar estas conexões como locais relativamente dúcteis da estrutura e eventualmente encontram apoio em engenheiros de soldagem desinformados. Portanto, neste artigo, intimamente relacionado com outros dois que publicamos [1, 2], também tentaremos demover ambos estes profissionais desta má prática de engenharia.

“Be ductile!"(“Seja dúctil!”). Foi com esta enfática expressão, que há cerca de 20 anos uma das autoridades na época da área sísmica de engenharia estrutural iniciou um artigo [3]. Apesar de ele ter sugerido ser este um básico e simples lema para sumarizar a filosofia do projeto sísmico, a importância da ductilidade pode ser resumida nas seguintes cinco afirmações [4] e, no nosso entender, para qualquer tipo de projeto (máquinas, veículos, estruturas, etc.): (a) permite a redistribuição das tensões internas e forças; (b) aumenta a resistência de membros, conexões e

Recebido em 17/10/2013, texto final em 17/10/2013. estruturas; (c) permite projeto baseado em modelos de equilíbrio simples; (d) resulta em estruturas mais robustas; (e) provê aviso de que uma falha ocorrerá; (f) permite que a estrutura sobreviva a severo carregamento produzido por terremoto.

Explicitando o nosso enfoque para esta complexa questão e exatamente ao que estamos nos referindo, vamos considerar a conceituação abrangente para ductilidade, que é a habilidade de sustentar grandes deformações inelásticas sem significativa perda de resistência, ou seja, a capacidade de deformação inelástica. Referindo-nos à Figura 1, esta "habilidade" deve ser do material; do componente estrutural (membros e conexões), caso do carregamento axial $(\Delta \mathrm{L})$; flexão da viga com as máximas flecha $(\delta)$ e rotação $(\theta)$, além do global (toda a estrutura), que exemplificamos pela deformação $(\Delta)$ do pórtico. Notemos que nesta figura o limite da curva pode ser tanto a fratura, quanto a instabilidade. Certamente entenderemos ainda melhor esta
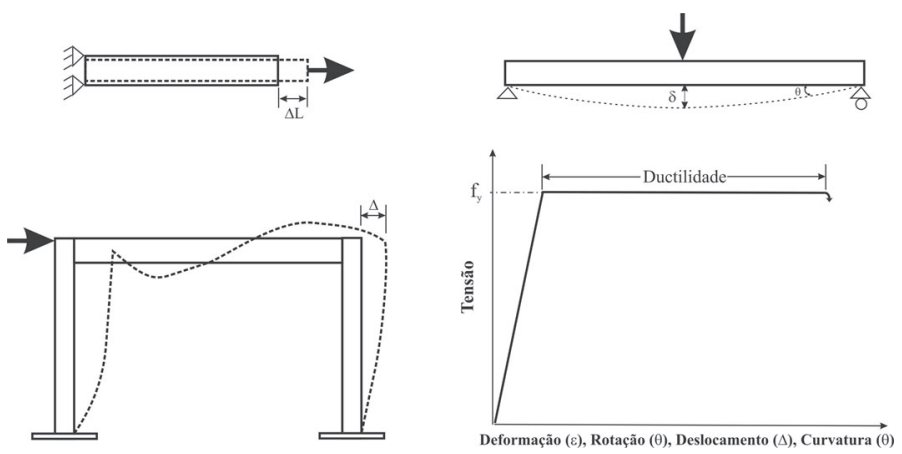

Figura 1 - Formas aparentes da ductilidade em diferentes escalas numa estrutura. 
questão com auxílio da simples, mas efetiva ideia [5] expressa através da corrente que mostramos na Figura 2. Como a resistência desta corrente é a do mais fraco dentre todos os elos, basta ele ser dúctil para que o sistema assim se comporte. Este elo dúctil apresenta incertezas quanto às propriedades mecânicas nominais e efeitos devido ao endurecimento (encruamento) por deformação quando esta é elevada. Os outros elos são presumivelmente "frágeis", mas as suas falhas podem ser prevenidas se as resistências que apresentam forem maiores do que a resistência real do elo dúctil no nível de ductilidade esperado.

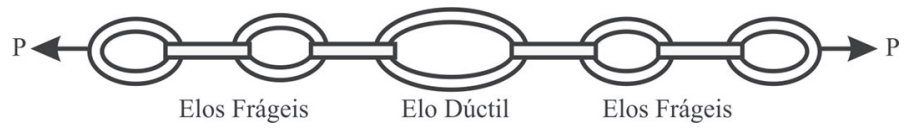

Figura 2 - Ductilidade de um sistema (corrente) determinada por um dos seus membros (elo) [5].

Mais especificamente para pórticos resistentes a momento, deformações inelásticas correspondem à formação de rótulas plásticas em certas posições e, portanto, a ductilidade disponível é associada com a capacidade de rotação destas rótulas [6]. Estas posições podem estar localizadas na zona do painel, nas conexões, ou nos membros, sendo este método conhecido como do componente e na Figura 3 apresentamos o conceito, o qual nos permite determinar a rotação total como a soma dos componentes e a ductilidade através daquela do componente menos resistente ("fraco").

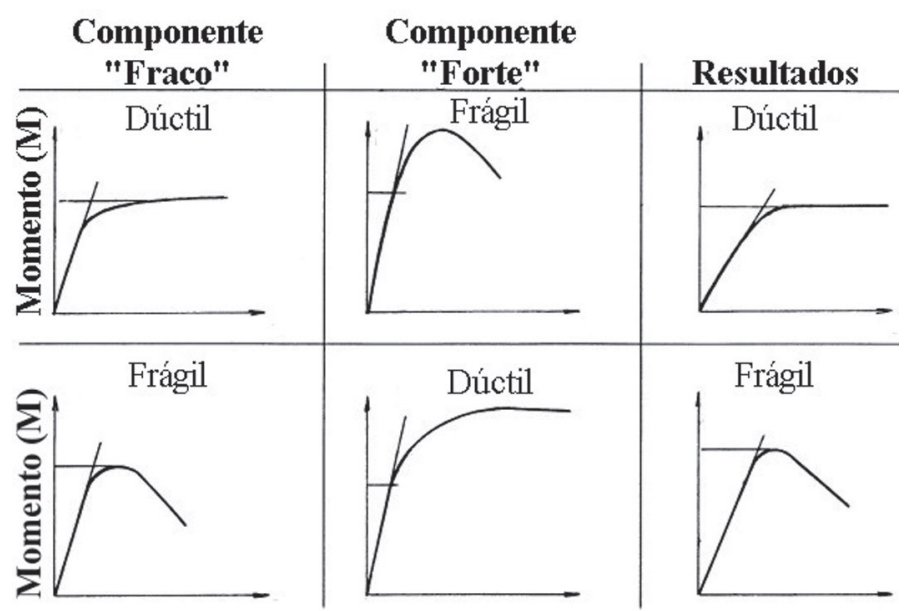

Rotação $(\theta)$

Figura 3 - Localização de rótulas plásticas em pórticos resistentes a momento [6].

Portanto, a aplicação correta do princípio do projeto baseado em capacidade de deformação (inelástica) requer o conhecimento das propriedades do material da zona plástica e vizinhanças, além da avaliação das tensões e deformações que têm que ser sustentadas pelo material desta zona plástica [7]. Voltaremos a discutir a questão das "incertezas" relativas às propriedades mecânicas nominais dos membros de uma estrutura, mas esta é uma das relativamente grandes alterações que as normas e os Códigos têm sofrido.
Por outro lado, quando apresentamos o termo "ductilidade" para engenheiros com formações diferentes, geralmente são distintos os conceitos que primeiro a eles ocorrem, mas há o fato em comum da maioria se referir ao material, ou seja: alguns relacionam ductilidade imediatamente com a energia absorvida no ensaio de impacto e/ou a aparência da superfície da fratura do material; outros visualizam esta propriedade como o alongamento num ensaio de tração uniaxial, ou também com a aparência da superfície da fratura do material, enquanto existem aqueles que pensam nos módulos de resiliência ou tenacidade, entre outras possibilidades.

Recordemos sucintamente, que tenacidade é o termo aceito para descrever a habilidade de um material em se deformar plasticamente e absorver energia antes e durante a ruptura em tensão de tração. Os adjetivos "frágil" e "dúctil" são usados para distinguir falhas ou materiais caracterizados por baixa e alta tenacidade, respectivamente [8]. A fratura frágil ocorre por início da trinca, com consequente propagação, crescimento e bifurcação, usualmente ao longo de planos cristalográficos preferenciais, através de ruptura das ligações atômicas, sendo suficiente a ação de tensão de tração e não há deformação plástica. Por outro lado, existindo associação da fratura com deformação plástica, ela é reconhecida como dúctil e seu mecanismo envolve formação de vazios, com posterior crescimento e coalescência, sendo a emissão de deslocamentos desde a extremidade da trinca um importante mecanismo para aumentar a tenacidade. Metais de grande pureza usualmente apresentam alta tenacidade e este tipo de fratura pode ocorrer por deformação plástica de planos de deslizamento conjugados em pura deformação por cisalhamento. Entretanto, nas ligas metálicas empregadas em engenharia existem inclusões, partículas de segunda fase, etc., que reduzem notavelmente a tenacidade. Então, a fratura inicia desde partículas que perdem coerência com a matriz, a qual sofre grande deformação plástica, se formando micro vazios que crescem por deslizamento. Num ensaio de tração, por exemplo, no limite da resistência a área da seção transversal diminui numa região localizada (sofre estricção) devido aos planos de deslizamento, em vez de em todo o comprimento do espécime, com as deformações causadas por tensão de cisalhamento.

Porém, em certas circunstâncias a deformação plástica é limitada (ou quase inexistente) e a energia consumida muito pequena. Esta situação pode ocorrer, por exemplo, em baixas temperaturas e/ou quando a taxa de aplicação da carga é excessivamente alta e/ou quando a fratura inicia sob relativamente baixa tensão num ponto de elevada concentração de tensões, principalmente se um estado de deformação plana reduz a possibilidade de deformação plástica (mais adiante voltaremos a esta questão). Nestes casos, a fratura ocorrerá de forma súbita e é frágil sob o ponto de vista de engenharia.

Por outro lado, os modernos conceitos de projeto considerando a questão da ductilidade, foram principalmente desenvolvidos para a construção de edificações (mais) resistentes a terremotos. Antes de aproximadamente 1960, ductilidade era um conceito usado somente para caracterização do comportamento do material com que uma estrutura seria fabricada. Isto se alterou a partir de estudos relacionados à dissipação de energia sísmica através de deformações plásticas 
[3, 9-11], sendo este conceito agora estendido para toda a estrutura e associado com sua resistência e rigidez. Então, apesar da nossa área de atuação ser a metal/mecânica, embasaremos parte da discussão sobre ductilidade na experiência adquirida pelos engenheiros estruturais, especializados em construções civis que sofreram, ou possivelmente sofrerão abalos sísmicos. É importante ressaltarmos serem eles os principais atores no atual cenário, buscam interpretar este fenômeno de forma abrangente e enfrentam a questão de forma inovadora. Não há nada surpreendente nisso, pois apesar de estar disperso, "o conhecimento é uno..." e iremos buscar as suas partes onde estiverem. Além disto, nas estruturas que sofrem ações estáticas deve ocorrer a redistribuição inelástica dos efeitos das cargas, enquanto no caso da análise sísmica, há necessidade de dissipação da energia. Portanto, ambas as situações são similares quanto ao desenvolvimento de ductilidade.

Adicionalmente, entendemos que devemos aprofundar o debate sobre esta questão, pois nossa experiência é de que alguns engenheiros não percebem adequadamente ser $o$ intensivo emprego dos aços (estruturais) em grande parte devido à característica ímpar deste material, de combinar relativamente elevadas resistência mecânica $e$ capacidade de deformação, dissipando, assim, energia. Esta "filosofia" é similar àquela da árvore, uma das maravilhosas obras de engenharia da natureza: quando o vento é intenso ela se curva (alonga) e, assim, usualmente não fratura...

Em suma, para enfatizar a questão, aos nossos acadêmicos e pós-graduandos de engenharia costumamos dizer que a fratura ocorrer de forma "dúctil", ou "frágil" pode significar a diferença entre a vida e a morte. E exemplificamos: se uma viga sobre os últimos assentos da sala de aula fraturar de forma dúctil, aqueles que lá estão sentados terão alguma chance de sobreviver, pois geralmente um ruído característico (a deformação) precederá a catástrofe, enquanto que se a fratura for frágil... Temos observado que após alguns minutos, vários daqueles que lá estão sentados sutilmente mudam-se para os primeiros assentos.

\section{Conceitos Essenciais e Exemplos}

O projeto de qualquer estrutura é idealizado através da adoção de uma dada "filosofia" - que, infelizmente, muitas vezes é transparente para alguns dos envolvidos no trabalho. Esta filosofia envolve diversas assertivas e provavelmente a mais importante é a opção pelo método de análise.

O conceito de que a estrutura sofrerá colapso, se em qualquer um dos seus pontos for excedido o limite de escoamento do material que a compõe, é considerado o método "clássico" de projeto em carregamento estático. Ele presume que a tensão para provocar a falha é, obrigatoriamente, maior do que aquela de escoamento. Entretanto, com a provável exceção dos membros sofrendo unicamente tensão de tração, o escoamento de outros pontos da estrutura não necessariamente provocará algum efeito sobre o todo. Além disto, evidentemente é possível um componente falhar com carga muito inferior do que aquela que provoca escoamento; basta para isto que ocorra "adequada" combinação de alguns fatores, ou seja, tensão, baixa ductilidade e existência de descontinuidade suficientemente severa. Portanto, este método usualmente utiliza somente pequena fração da resistência realmente disponível do material, pois admite a possibilidade da ativação de outros fatores — desconhecidos, ou impossíveis de serem quantificados.

As estruturas também podem ser projetadas sob o princípio do estado limite, ou o cálculo da carga necessária para que ela colapse, não sendo necessário estimarmos as distribuições de tensões, fato que simplifica significativamente a análise, principalmente em casos estaticamente indeterminados. Assim, usualmente o material é idealizado comportando-se de forma elástica até o limite de escoamento e, então, deforma-se (plasticamente) sem alteração da tensão, ou seja, o material é elástico perfeitamente plástico ou elastoplástico. Como a maioria dos aços estruturais sofrem endurecimento (encruamento) por deformação após o limite de escoamento, a resistência destes materiais é mais elevada do que aquela considerada no modelo sendo o projeto inerentemente seguro. Entretanto, como o estado limite presume que há tolerância ao escoamento nas regiões mais tensionadas, o seu uso é restrito a algumas aplicações e geralmente não é aceitável para casos de flambagem elástica e fadiga, entre outros.

Por sua vez, conceitos de mecânica da fratura encontram aplicação em algumas importantes situações, nas quais geralmente são bem conhecidas as propriedades mecânicas e metalúrgicas reais (não "nominais") dos materiais envolvidos e as cargas atuantes, bem como quando é possível estimarmos com razoável precisão o comportamento das descontinuidades. Entretanto, nem sempre podemos utilizar este método para estruturas soldadas complexas, com as incertezas que usualmente cercam as propriedades mecânicas e cujas questões envolvendo efeitos dos entalhes ainda não estão completamente resolvidas, ou cujas soluções somente contemplem tratamento elástico. Porém, é útil usarmos como modelo o fato de que as tensões aplicadas normais, o tamanho tolerável e a forma da trinca podem ser relacionados com a tenacidade à fratura $\left(\mathrm{K}_{\mathrm{c}}\right)$ do material. Portanto, conhecendo o $\mathrm{K}_{\mathrm{c}}$ de um dado material com particular espessura, numa dada temperatura e específica taxa de carregamento, o projetista pode determinar o tamanho da trinca que é tolerável num membro estrutural, para uma tensão de projeto sem início de fratura frágil. O inverso também é verdadeiro, ou seja, para uma dada tensão de projeto e tamanho de trinca num componente estrutural, o projetista pode especificar um valor de $\mathrm{K}_{\mathrm{c}}$ que provê adequada segurança e confiabilidade. Entretanto, à frente da extremidade de uma trinca o constrangimento lateral é tal, que existem tensões na espessura e elas têm que ser zero em cada superfície livre. Então, para peças relativamente finas estas tensões são menores do que nas grossas e ocorrendo estado tri-axial de tensão de tração à frente da extremidade da trinca, a deformação plástica é constrangida, sendo reduzida a aparente ductilidade e tenacidade à fratura do material, ainda que as propriedades metalúrgicas das peças sejam idênticas. Portanto, a tenacidade à fratura decresce conforme aumenta a espessura da peça, conforme mencionamos em [2], sendo seu valor mínimo $\left(\mathrm{K}_{\mathrm{Ic}}\right)$ alcançado quando ela é espessa o suficiente para estabelecer um estado de tensão de deformação plana, dado (conservadoramente) por $2,5\left(\mathrm{~K}_{\mathrm{Ic}} / \mathrm{f}_{\mathrm{y}}\right)^{2}$, onde $\mathrm{f}_{\mathrm{y}}$ é o limite do escoamento. Esta é a denominada "inerente" propriedade do 
material.

Entretanto, aqui estamos interessados em compreender com maiores detalhes como se desenvolve a ductilidade, de forma a empregarmos este princípio nas estruturas. Para tanto, na Figura 4 mostramos esquematicamente alguns característicos diagramas tensão-deformação em ensaio de tração uniaxial, os quais nos ajudarão a convencionar a terminologia e apresentar situações que serão úteis no restante deste artigo. Os diagramas tensão-deformação de engenharia (convencional) e verdadeiro, tal como aqueles que esquematicamente apresentamos na Figura 4(a), podem representar o comportamento típico de aço estrutural (dúctil), sendo que em parte eles se confundem. Como sabemos, a diferença de comportamento apresentada pelos diagramas deve-se a que naquele de engenharia, a resistência à tração é definida como a máxima tensão relacionada com a área da seção original $\left(\mathrm{A}_{0}\right)$ do espécime, sendo nominal a tensão e a deformação $\left(\varepsilon_{n}\right)$. Porém, o diagrama tensão-deformação verdadeiro resulta dos valores correlacionados da tensão, da área da seção transversal (A) e deformação $(\varepsilon)$. Portanto, nesta situação esta deformação é uma constante real do material independente do espécime ensaiado, sendo relacionada com a nominal por $\varepsilon=\ln \left(\mathrm{A}_{0} / \mathrm{A}\right)=\ln \left(1+\varepsilon_{\mathrm{n}}\right)$.

No diagrama de engenharia da Figura 4(a), f é o limite de escoamento (superior) e existindo logo abaixo dele (mas não mostrado nesta figura) o limite de proporcionalidade, enquanto $f_{u}$ é o limite da resistência à tração, correspondendo a ambos as deformações $\varepsilon_{\mathrm{y}}$ e $\varepsilon_{\mathrm{u}}$, respectivamente. Considerando este diagrama distinguimos quatro regiões, ou seja: I com comportamento elástico, admitindo-se que ocorra até $\mathrm{f}_{\mathrm{y}}$;

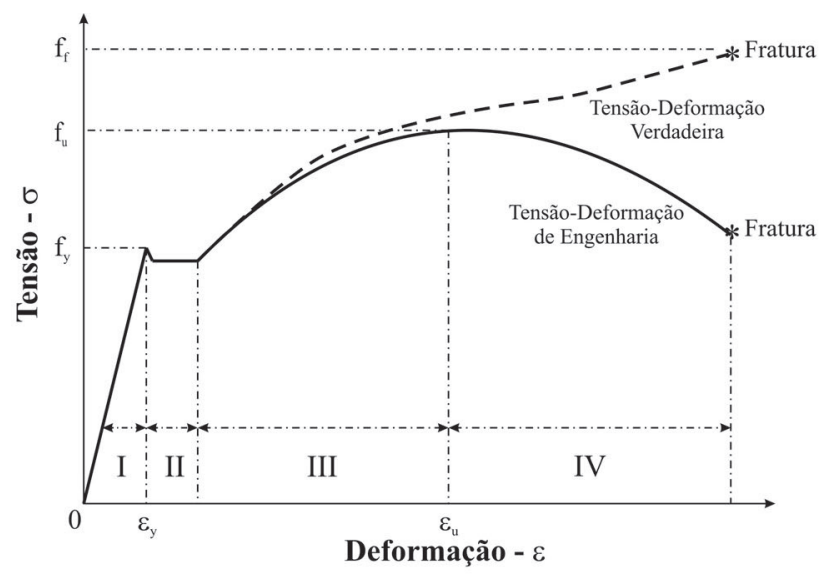

(a)

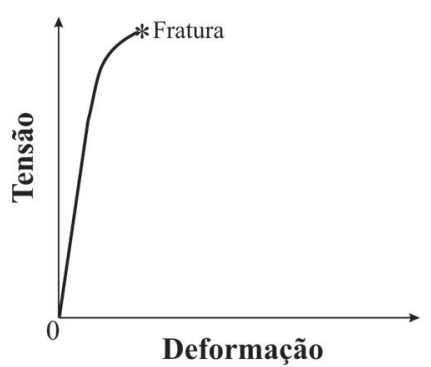

(c)

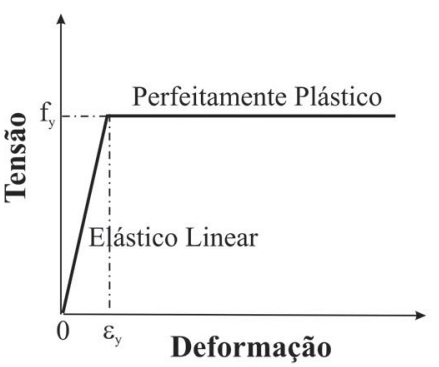

(d)

II onde há escoamento e a deformação é permanente; III com endurecimento (encruamento) por deformação até $f_{u}$ ser alcançado, sendo a deformação do corpo de prova aproximadamente homogênea (em toda a sua extensão) até este ponto; IV onde inicia deformação localizada (redução do diâmetro, ou estricção) no corpo de prova, provocada por planos que deslizam no interior do material e atuando tensões de cisalhamento. Então, o aço possui comportamento elástico na região I e plástico nas regiões II, III e IV. Na Figura 4(b) mostramos três diagramas de engenharia para aços estruturais [12], sendo interessante observarmos que, conforme aumenta o limite (nominal) do escoamento, o alongamento sofre notável redução.

Neste ponto faz-se mister esclarecermos uma questão recorrente, que se refere ao por que da exigência da razão ( $\mathrm{f}_{\mathrm{y}} /$ $\left.\mathrm{f}_{\mathrm{u}}\right) \leq(1 / 1,10) \approx 0,90$, ou outros valores (próximos) em diferentes normas, para o emprego dos aços estruturais, como mencionamos em [2]. Para isto, devemos recordar que os aços estruturais (e metais em geral) endurecem com a deformação e ela deve ser redistribuída; ocorrendo acumulação de deslocamentos num dado local com capacidade de carga maior do que nas regiões vizinhas. Como consequência, o escoamento plástico é maior nas regiões não endurecidas (encruadas) e a deformação sofre redistribuição. Por outro lado, a capacidade de deformação não é infinita e existem várias formas para sua interrupção, sendo que conhecemos como fratura o conjunto de fenômenos que cooperam para isto. Um dos fatores que limitam a habilidade da redistribuição da deformação é a geometria da peça; por exemplo, numa peça tracionada há progressiva redução da sua

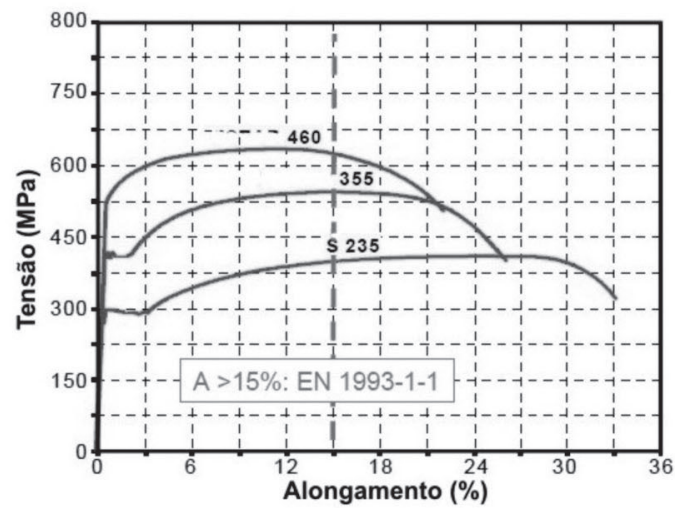

(b)

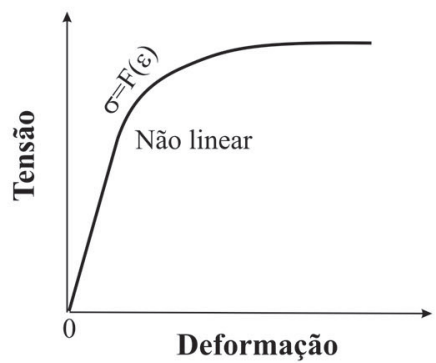

(e)

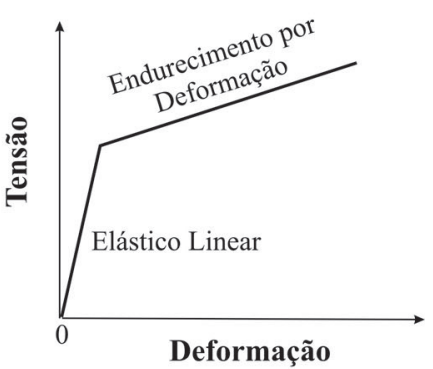

(f)

Figura 4 - Diagramas tensão-deformação: (a) esquemático para um aço baixo carbono, mostrando o tipo de engenharia e verdadeiro; (b) de engenharia para aços estruturais; (c) a (f) esquemáticos para diferentes casos. 
seção transversal, existindo competição entre o endurecimento por deformação e o escoamento plástico devido à geometria. Quando o endurecimento por deformação não acompanha mais este escoamento plástico, há início da estricção. O critério para instabilidade é que o aumento da carga em qualquer elemento do material é menor ou igual a zero. Então, sendo a carga no espécime tracionado $\mathrm{F}=\mathrm{A} . \sigma$, a máxima tensão $\left(\mathrm{f}_{\mathrm{u}}\right)$ é alcançada no ponto em que $\mathrm{dF}=\mathrm{A} \cdot \mathrm{d} \sigma+\sigma \cdot \mathrm{dA}=0$ e, portanto, $(\mathrm{d} \sigma / \sigma)=(-\mathrm{dA} / \mathrm{A})$, com o aumento da carga positivo em endurecimento por deformação dominando no início do processo e a alteração da área da seção transversal negativo. Isto leva ao critério da instabilidade para a resistência à tração, em que $(\mathrm{d} \sigma / \mathrm{d} \varepsilon)=\sigma$, ou seja, a taxa com que ocorre o endurecimento é igual à tensão (verdadeira) no ponto em que o material não mais suporta aumento da carga e, além deste ponto sobre o diagrama tensão-deformação, a deformação tende a se localizar na região de estricção. Desta forma, a "estabilidade da resistência" $\left(\mathrm{f}_{\mathrm{u}}\right)$ resultante deste critério leva às máximas deformações $\left(\varepsilon_{u}\right)$, as quais automaticamente são menores, tanto quanto maior for o limite de escoamento do material. Portanto, a razão $f_{\mathrm{y}} / \mathrm{f}_{\mathrm{u}}$ depende da magnitude do limite de escoamento, conforme mostramos na Figura 5 para diferentes aços estruturais [12]. Uma importante consequência deste fato —em conjunto com a constatação de que a tenacidade requerida para aços de alta resistência é significativamente maior do que para aços de menor resistência-, é que quanto maior for a razão $f_{y} / f_{u}$, tanto menor será o tamanho das falhas ou entalhes permitidos no material.

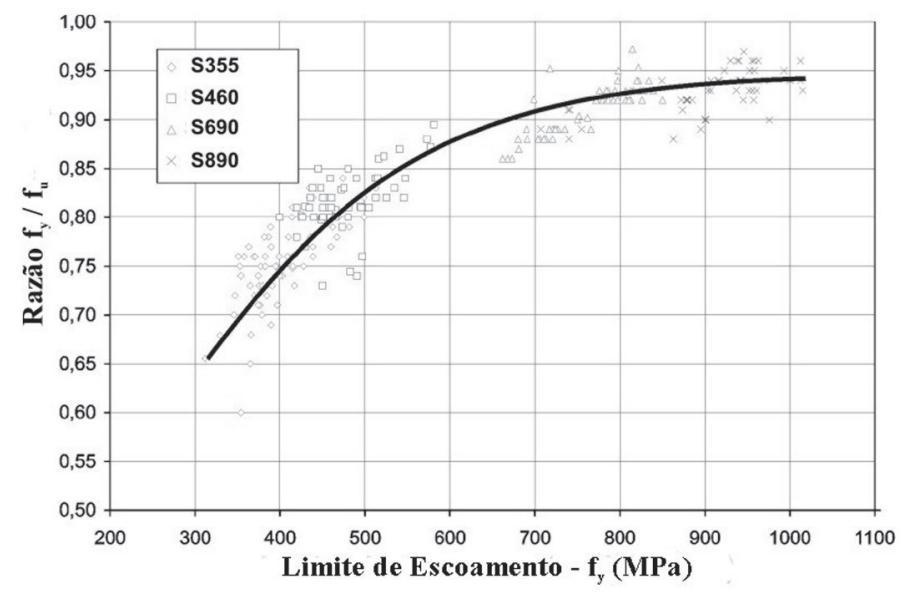

Figura 5 - Influência do limite de escoamento sobre a razão do seu valor e da resistência à tração para diversos aços estruturais [12].

Como exemplo de comportamento completamente diferente dos aços estruturais, mostramos aquele da Figura 4(c), o qual é típico de material frágil, tal como ferro fundido em tensão de tração. Notemos que o alongamento (elástico) é muito pequeno, com região plástica nula, ou praticamente inexistente.

Por sua vez, geralmente utilizamos curvas idealizadas para análise e projeto, sendo que abaixo estão quatro tipos importantes:

- Figura 4(d): como os aços estruturais possuem uma região elástica linear seguida de outra onde ocorre relativamente grande deformação, este diagrama bi linear é usualmente empregado (tração ou compressão), sendo este comportamento conhecido como elástico perfeitamente plástico (elastoplástico). Neste caso, supomos que o material é elástico-linear (segue a "lei de Hooke") até o limite do escoamento e, após, escoa em tensão constante, tal como na região II da Figura 4(a), sendo então a deformação dada pela soma dos componentes elástico $\left(\varepsilon_{\mathrm{e}}\right) \mathrm{e}$ plástico $\left(\varepsilon_{\mathrm{p}}\right)$, como veremos mais adiante. Em aços estruturais, a deformação nesta região pode ser maior do que cerca de 15 vezes a do escoamento.

- Figura 4(e): este é o caso típico não linear geral em que há endurecimento por deformação e é desprezível a deformação elástica perante a plástica. Provavelmente a expressão matemática mais conhecida é aquela dada pela "lei de RambergOsgood", a qual para ensaios de tração é geralmente usada com valores verdadeiros de tensões e deformações.

- Figura 4(f): esta é uma relação bi linear, existindo comportamento linear de endurecimento com a deformação. Uma reta mantém proporcionalidade entre tensão e deformação (inclinação E), enquanto a outra sofre aumento da tensão após o escoamento, com inclinação $\delta$.E, onde $\mathrm{E}$ é o módulo de elasticidade e $\delta$ um fator de redução $(0 \leq \delta \leq 1)$.

A seguir vamos analisar alguns princípios fundamentais da deformação plástica, pois essencialmente são duas as principais situações que envolvem questões relacionadas com a ductilidade.

O primeiro caso refere-se à análise plástica de estruturas, onde elementos específicos são escolhidos e projetados de forma a dissipar o máximo de energia, quando sobre eles atuam severas deformações. As regiões críticas destes membros, geralmente denominadas rótulas plásticas ou regiões de dissipação, são detalhadas para comportamento inelástico. Desta forma, todos os outros membros estruturais são protegidos das ações que poderiam causar falha, provendo-os com resistência maior do que aquela correspondente ao desenvolvimento da máxima (viável) resistência na região da rótula plástica e ilustramos este conceito no início deste artigo. Para análise plástica global dos aços estruturais, uma relação bi linear elástica perfeitamente plástica tensão-deformação pode ser adotada [13, por exemplo], com os Códigos ou normas apresentando diversas particularidades.

Por outro lado, em diversas situações no projeto de estruturas, máquinas, etc., ocorre deformação além do limite de escoamento e, então, não há mais proporcionalidade entre carga (ou tensão) e deformação. Se esta deformação não tiver grande dependência do tempo, ela é denominada plástica e aqui reside o nosso interesse, pois existindo forte dependência do tempo estaremos diante de outro fenômeno, ou seja, fluência.

Em materiais dúcteis, a região na qual não ocorre falha é independente da tensão normal e é definida pela máxima tensão de cisalhamento deste material (numa específica situação). Isto é consistente com o critério de von Mises ou da energia de distorção máxima (vide abaixo). Por sua vez, para materiais frágeis, a região em que não ocorre falha é função da tensão normal e da tensão de cisalhamento. Quanto maior a tensão de compressão, mais elevada é a resistência do material a tensão de cisalhamento; porém, sendo dominante a tensão de tração, a falha se deve somente a ela. A existência de componentes de tensão em mais do que uma direção afeta a rigidez elástica e 
o limite de escoamento de um material. Durante deformação plástica, o estado de tensão continua a afetar o comportamento e a teoria elástica para deformação se aplica não somente antes do escoamento, mas também após ele ocorrer.

A seguir apresentaremos algumas relações de interesse para entendermos a deformação plástica, com os subscritos $(1,2,3)$ indicando os eixos coordenados $(\mathrm{x}, \mathrm{y}, \mathrm{z})$ que estão nas direções das tensões principais. A breve discussão que se segue visa somente apresentar alguns elementos básicos, para possibilitar aquele leitor que não conhece este assunto acompanhar o desenvolvimento sem grande prejuízo. Sugerimos que este leitor recorra a um bom livro de resistência dos materiais e recomendamos dois clássicos, sendo o primeiro mais geral, mas mesmo com o passar do tempo imbatível [14] e o outro bastante específico [15].

Então, num ensaio de tração uniaxial com $\sigma_{1}=\mathrm{f}_{\mathrm{y}}$ e $\sigma_{2}=\sigma_{3}=0$, na face do corpo de prova ortogonal à carga, a tensão de escoamento em cisalhamento $\tau_{\mathrm{y}}$ é dada pela Equação 1 (critério de escoamento de Tresca), enquanto considerando o critério de von Mises a tensão de cisalhamento equivalente $\left(\tau_{\mathrm{e}}\right)$ pode ser obtida desde a Equação 2 e há escoamento (em cisalhamento) quando ela é alcançada.

$$
\begin{aligned}
& \tau_{y}=\frac{f_{y}}{2} \\
& \tau_{e}=\frac{\sqrt{2}}{3} f_{y}
\end{aligned}
$$

Para um dado material, o critério de von Mises prevê que o escoamento ocorre quando é alcançado a tensão efetiva $\left(\sigma_{\mathrm{e}}\right)$, a qual podemos expressar como função das tensões normais principais, conforme Equação 3, ou pela Equação 4 para qualquer estado de tensão sem a necessidade de determinarmos as tensões principais.

$$
\begin{aligned}
& \sigma_{e}=\frac{1}{\sqrt{2}} \sqrt{\left(\sigma_{1}-\sigma_{2}\right)^{2}+\left(\sigma_{2}-\sigma_{3}\right)^{2}+\left(\sigma_{3}-\sigma_{1}\right)^{2}} \\
& \sigma_{e}=\frac{1}{\sqrt{2}} \sqrt{\left(\sigma_{x}-\sigma_{y}\right)^{2}+\left(\sigma_{y}-\sigma_{z}\right)^{2}+\left(\sigma_{z}-\sigma_{x}\right)^{2}+6\left(\tau_{x y}^{2}+\tau_{y z}^{2}+\tau_{z x}^{2}\right)}
\end{aligned}
$$

Por sua vez, a deformação plástica efetiva $\left(\varepsilon_{\mathrm{pe}}\right)$ é função das deformações plástica nas direções principais, sendo expressa pela Equação 5.

$$
\varepsilon_{p e}=\frac{\sqrt{2}}{3} \sqrt{\left(\varepsilon_{p 1}-\varepsilon_{p 2}\right)^{2}+\left(\varepsilon_{p 2}-\varepsilon_{p 3}\right)^{2}+\left(\varepsilon_{p 3}-\varepsilon_{p 1}\right)^{2}}
$$

Então, a deformação total efetiva $\left(\varepsilon_{\mathrm{te}}\right)$ é a soma das partes elástica e plástica, conforme Equação 6 , sendo para o caso uniaxial $\varepsilon_{\mathrm{te}}=\varepsilon_{1}$.

$$
\varepsilon_{t e}=\frac{\sigma_{e}}{E}+\varepsilon_{p e}
$$

Assim, a teoria da deformação possui uma característica deveras importante, ou seja, uma única relação entre $\sigma_{\mathrm{e}}$ e $\varepsilon_{\mathrm{te}}$ para todos os estados de tensão.
As relações entre tensões e deformações plásticas são análogas àquelas empregadas na teoria elástica, porém 0 coeficiente de Poisson é 0,5 , pois as deformações plásticas não contribuem para alteração volumétrica, além do módulo de elasticidade (E) ser substituído por um "módulo de plasticidade" $\mathrm{E}_{\mathrm{p}}=\sigma_{\mathrm{e}} / \varepsilon_{\mathrm{pe}}$. Desta forma, os componentes das deformações totais podem ser expressos pelas Equações 7.

$$
\begin{gathered}
\varepsilon_{x}=\frac{1}{E_{t}}\left[\sigma_{x}-v_{g}\left(\sigma_{y}+\sigma_{z}\right)\right] \\
\varepsilon_{y}=\frac{1}{E_{t}}\left[\sigma_{y}-v_{g}\left(\sigma_{x}+\sigma_{z}\right)\right] \\
\varepsilon_{z}=\frac{1}{E_{t}}\left[\sigma_{z}-v_{g}\left(\sigma_{x}+\sigma_{y}\right)\right]
\end{gathered}
$$

Aqui $\mathrm{E}_{\mathrm{t}}=\sigma_{\mathrm{e}} / \varepsilon_{\mathrm{te}}$ é o módulo secante para um ponto sobre a curva que relaciona a tensão efetiva e a deformação total efetiva, enquanto que $v_{\mathrm{g}}=\left(\nu \cdot \sigma_{\mathrm{e}}+0,5 \mathrm{E} \cdot \varepsilon_{\mathrm{pe}}\right) /\left(\mathrm{E} \cdot \varepsilon_{\mathrm{pe}}\right)$ pode ser interpretado como o coeficiente de Poisson generalizado, cujo valor depende da repartição da deformação total efetiva entre os componentes elástico e plástico. Portanto, $v_{\mathrm{g}}$ varia entre $v$ para deformação relativamente pequena e 0,5 quando a deformação plástica domina.

Desta forma, considerando os eixos coordenados como principais, a deformação total efetiva pode ser expressa pelas deformações totais nas direções principais, como mostramos na Equação 8, como alternativa à Equação 6.

$$
\varepsilon_{t e}=\frac{1}{\left(1+v_{g}\right) \sqrt{2}} \sqrt{\left(\varepsilon_{1}-\varepsilon_{2}\right)^{2}+\left(\varepsilon_{2}-\varepsilon_{3}\right)^{2}+\left(\varepsilon_{3}-\varepsilon_{1}\right)^{2}}
$$

Estas são, então, as equações básicas da deformação e com elas podemos resolver alguns problemas elementares.

Vamos agora apresentar alguns exemplos muito simples, comparando materiais frágeis e dúcteis em membros de uma estrutura e verificar que este fenômeno é similar àquele ocorre em juntas soldadas.

Começaremos com membros de mesma geometria em tensão de tração, existindo efeito de entalhe (causado pela variação da largura) conforme Figura 6(a), com o problema sendo encontrar a máxima carga $\left(\mathrm{P}_{\max }\right)$ que pode ser aplicada em cada caso. A espessura do membro é $\mathrm{t}=10 \mathrm{~mm} ; \mathrm{L}_{1}=100 \mathrm{~mm}$; $\mathrm{L}_{2}=200 \mathrm{~mm}$ e $\mathrm{R}=10 \mathrm{~mm}$. Portanto, $\mathrm{R} / \mathrm{L}_{1}=0,1$ e $\mathrm{L}_{2} / \mathrm{L}_{1}=2$. Para o material frágil o fator de concentração de tensão elástico resulta em $k_{t}=2,5$, podendo ser obtido, por exemplo, em [16]. A tensão "média" é tomada como $\sigma=\mathrm{P} /\left(\mathrm{t} . \mathrm{L}_{2}\right)=\mathrm{P} / 2000$ e para este exemplo, consideramos que a máxima tensão $\left(\sigma_{\text {max }}\right)$ permitida em cada caso é: para o material frágil, a sua resistência à tração $\mathrm{f}=350$ $\mathrm{MPa}$, quando sofre fratura conforme Figura 4(c); para o material dúctil um valor idêntico, mas ao do seu limite de escoamento $\mathrm{f}_{\mathrm{y}}=350 \mathrm{MPa}$, conforme ilustramos na Figura 4(d).

Então, na Figura 6(b) mostramos a concentração de tensões provocada por esta situação no material com comportamento frágil. A carga máxima $\left(\mathrm{P}_{\max }\right)$ permitida é, portanto, aquela dada pela Equação 9.

$$
\sigma_{\max }=f_{u}=350=k_{t} \cdot \sigma=2,5 \cdot \frac{P_{\max }}{2000} \therefore P_{\max }=280 \mathrm{kN}
$$




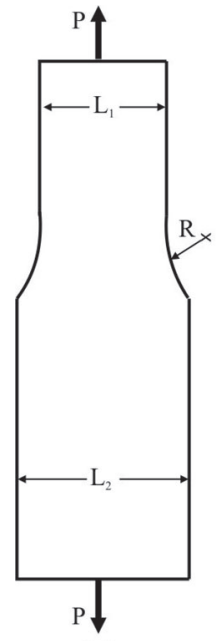

(a)

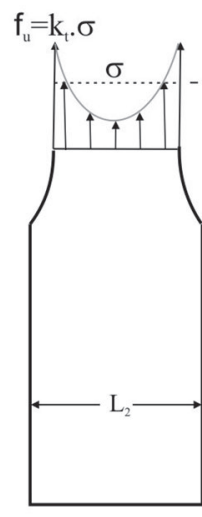

(b)

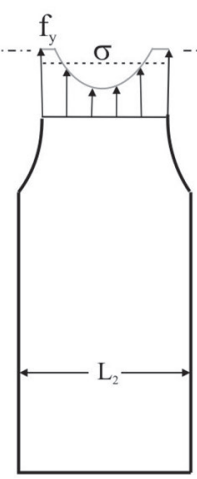

(c)

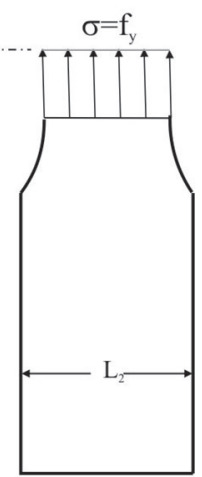

(d)
Figura 6 - (a) membro em tensão de tração com entalhe; (b) concentração de tensões no entalhe em membro frágil; (c, d) membro dúctil com escoamento local e completo no entalhe, respectivamente.

Por sua vez, o material dúctil pode apresentar escoamento local ou completo, com as distribuições de tensões como podemos ver na Figura 6(c) e Figura 6(d), respectivamente. Desta forma, existindo escoamento completo, a carga máxima é dada pela Equação 10.

$$
\sigma_{\text {max }}=f_{y}=350=\frac{P_{\max }}{t \cdot L_{2}}=\frac{P_{\max }}{2000} \quad \therefore \quad P_{\max }=700 \mathrm{kN}(10)
$$

Portanto, mesmo que o material dúctil apresente menor resistência à tração do que o frágil, ele suporta carga maior, pois há entalhe no membro. Este entalhe é similar a, por exemplo, o pé ou a raiz da solda e evidencia-se, assim, a vantagem do material base ser muito dúctil numa estrutura soldada.

Por outro lado, podemos entender a formação de rótulas plásticas através de uma viga retangular sob momento (M) constante, conforme mostramos esquematicamente na Figura 7 (a), sendo b=150 $\mathrm{mm}$ e $\mathrm{h}=400 \mathrm{~mm}$. Em flexão pura a máxima tensão normal $\left(\sigma_{\max }\right)$ ocorre em $\pm \mathrm{h} / 2$, existindo escoamento quando ela alcança o limite de escoamento, ou seja, $\sigma_{\text {max }}= \pm f_{y}$ (compressão e tensão).

Tal como no exemplo anterior, mas agora buscando o valor do máximo momento que pode ser aplicado, vamos considerar duas vigas compostas por dois materiais, cuja máxima tensão $\left(\sigma_{\max }\right)$ permitida em cada caso é: para o material frágil, a sua resistência à tração $\mathrm{f}_{\mathrm{u}}=350 \mathrm{MPa}$, quando sofre fratura conforme Figura 4(c); para o material dúctil um valor idêntico, mas ao do seu limite de escoamento $\mathrm{f}_{\mathrm{y}}=350 \mathrm{MPa}$, tal como ilustramos na Figura 4(d).

Então, para o material frágil o dimensionamento deve ser elástico, como mostramos esquematicamente nas Figuras 7(b, e). O módulo elástico da seção retangular é $\mathrm{W}=\mathrm{I} /(\mathrm{h} / 2)=\mathrm{b} \cdot \mathrm{h}^{2} / 6=4 \cdot 10^{-3} \mathrm{~m}^{3}$, onde I é o momento de inércia da seção e o momento máximo de acordo com a Equação 11.

$M_{\max }=\sigma_{\max } \cdot W=350 \cdot 4 \cdot 10^{-3} \therefore M_{\max }=1400 \mathrm{kN} \cdot \mathrm{m}(11)$

O material dúctil pode apresentar escoamento local, Figura 7(c) ou completo, Figura 7(d), com as distribuições de tensões na Figura 7(f). A magnitude do momento suportado pela porção plástica da seção transversal $\left(\mathrm{M}_{\mathrm{p}}\right)$ é dada pela Equação 12, onde $\mathrm{Z}=\mathrm{b} \cdot \mathrm{h}^{2} / 4=6 \cdot 10^{-3} \mathrm{~m}^{3}$ é o módulo plástico da seção.

$M_{p}=M_{\max }=f_{y} \cdot Z=350 \cdot 6 \cdot 10^{-3} \therefore M_{\max }=2100 \mathrm{kN} \cdot \mathrm{m}$

Desta forma, o momento máximo suportado por esta viga retangular em material dúctil é 1,5 vezes maior do que quando o material é frágil. Evidentemente este fator varia em função do perfil utilizado para a viga; no tipo "I" e dimensões padronizadas, por exemplo, ele usualmente encontra-se entre 1,15 e 1,17.

Portanto, num material com características dúcteis o escoamento "alivia" as concentrações de tensões e a carga aplicada pode ser muito maior do que aquela permitida no material frágil.

Esta situação não é idêntica, mas similar a junta soldada de filete, como ilustramos na Figura 8. Quando o material é (relativamente) frágil, a tensão máxima $\left(\sigma_{\max }\right)$ na raiz do cordão de solda resulta do produto do fator de concentração de tensão $\left(\mathrm{k}_{\mathrm{t}}\right)$ pela tensão aplicada $(\sigma)$ e usualmente fratura com baixo $\sigma_{\max }$. Entretanto, sendo o material dúctil, há escoamento local e redistribuição das tensões. Esta é uma questão que mencionamos em artigos anteriores [1,2], pois se as regiões dos pés e da raiz das soldas não escoassem, estas juntas sofreriam invariavelmente fratura com aplicação de pequena carga.

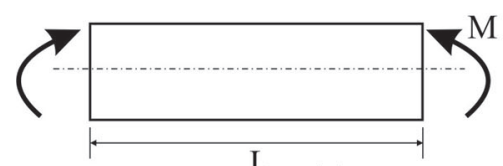

(a)
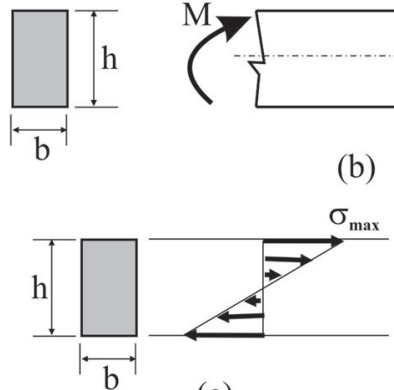

(e)

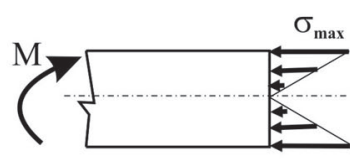

(b)

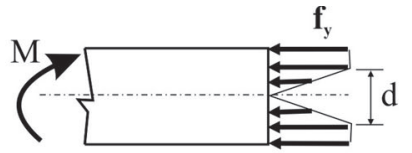

(c)

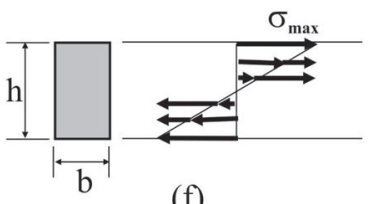

(f)

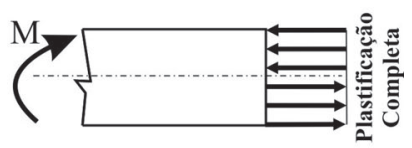

(d)

Figura 7 - (a) representação esquemática de viga retangular sob momento constante; (b, e) distribuição de tensões para um material frágil, com dimensionamento elástico; $(\mathrm{c}, \mathrm{d}, \mathrm{f})$ idem para um material dúctil. 


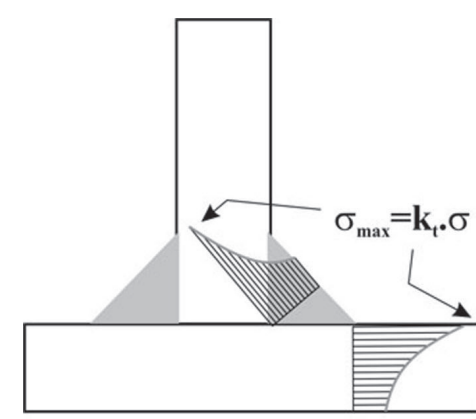

Elástico

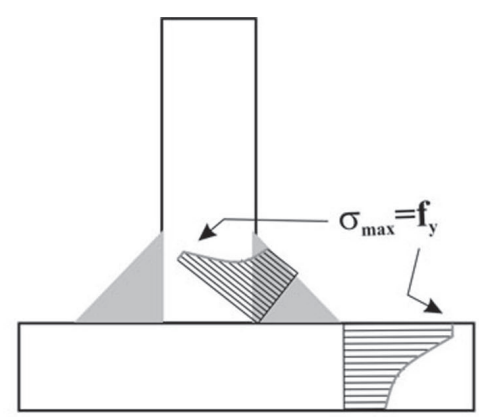

Elástico-Plástico

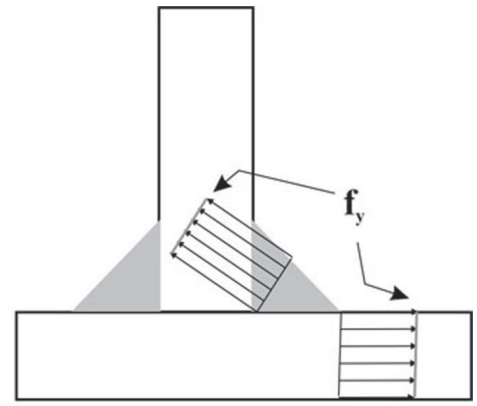

Plástico

Figura 8 - Distribuição de tensões em soldas de filete através de diferentes tipos de análise.

Por outro lado, há situações que naturalmente geram grandes tensões residuais, tal como aquela da soldagem entre coluna e viga, que ilustramos na Figura 9. Na direção longitudinal do cordão de solda, a sua contração no resfriamento é quase totalmente impedida pelas mesas de ambos os componentes, condição que desenvolve elevadas tensões residuais paralelas ao cordão - tanto no metal de solda, quanto no metal base-, as quais podem alcançar o limite do escoamento destes materiais. Adicionalmente, sendo as mesas muito espessas também podem se desenvolver tensões ortogonais a elas, resultando em redução da ductilidade local na viga, próximo ao cordão de solda. Isto ocorre porque para ocorrer escoamento é necessário o desenvolvimento de planos de deslizamento, fato que implica na tensão de cisalhamento ser excedida, conforme indicamos nesta figura. Em outras palavras, tensões residuais bi ou tri-axial reduzem as tensões de cisalhamento e impedem comportamento plástico, criando condições para fratura frágil [7]. Conforme veremos, esta é (mais) uma razão para afastarmos a rótula plástica (vide a seguir) da região da conexão soldada. Entretanto, tanto nesta situação, quanto na anterior, se o metal de solda possuir elevada ductilidade as chances de ocorrer fratura frágil são minimizadas.

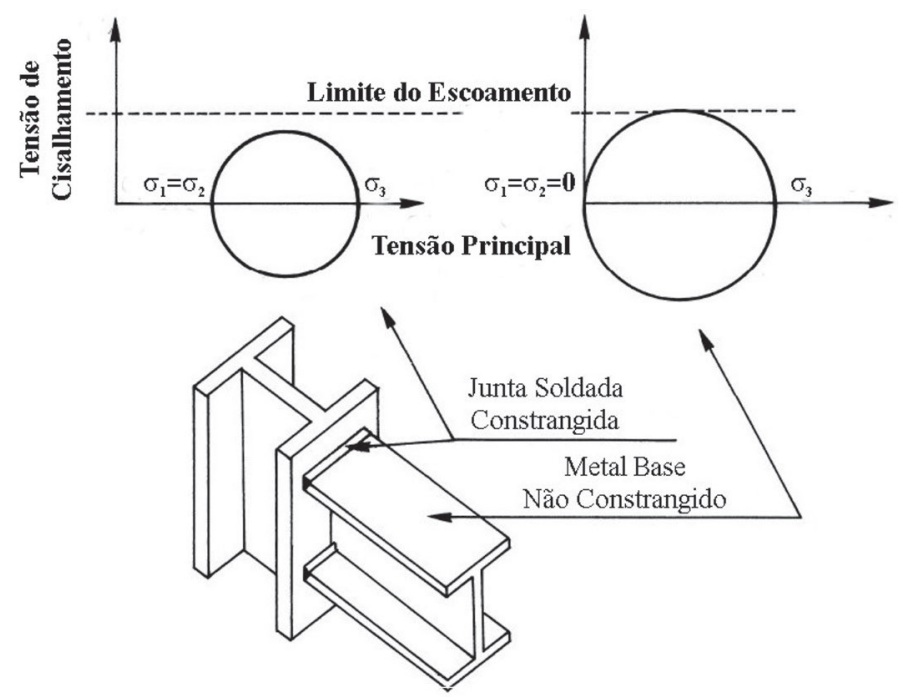

Figura 9 - Representação esquemática da geração de tensões residuais em junta soldada entre coluna e viga [7].

\section{Reduzida Ductilidade e Falhas}

Em artigo anterior [2] mencionamos que é possível ocorrer excessivo constrangimento dos membros da estrutura, ou das juntas soldadas, devido a inesperadas condições de serviço, ou criadas pelo próprio projetista. Dada a importância da questão, repetimos aqui que ductilidade não é uma propriedade mecânica "líquida e certa" e sugerimos ao leitor que verifique naquele artigo as principais razões para isto assim ser. Então, um material "frágil" em tensão de tração continuará a ter este comportamento numa estrutura em ambiente e carregamento similar, enquanto um material "dúctil" neste ensaio poderá responder de forma "frágil", devido a outros fatores.

Enfatizamos que aqui não estamos considerando ductilidade somente sob um "ponto de vista", mas através dos seus diversos "tipos", conforme ilustramos na Figura 10, ou seja: (a) ductilidade do material ou axial, a qual caracteriza as deformações plásticas do material; (b) ductilidade da seção transversal ou de curvatura, a qual se refere às deformações plásticas da seção transversal, considerando a interação entre as partes que compõem a própria seção transversal; (c) ductilidade do membro ou de rotação, quando as propriedades do membro são consideradas; (d) ductilidade da estrutura ou de deslocamento, a qual considera o comportamento de toda a estrutura. Nesta Figura 10 " $\mu$ " define a ductilidade, enquanto o subscrito "u" refere-se à máxima deformação (alongamento, curvatura, rotação, deslocamento, etc.) e o subscrito " $y$ " indica a deformação para o (primeiro) escoamento. Exemplificando, a ductilidade do membro $\left(\mu_{\theta}\right)$ é avaliada através da razão entre as rotações na fratura $\left(\theta_{u}\right)$ e aquela no primeiro escoamento $\left(\theta_{\mathrm{y}}\right)$, ambas provocadas pelo momento resultante de uma carga aplicada na viga. Além disto, por exemplo, o colapso de um elemento pode ocorrer através de deformação plástica, limitada por flambagem, ou por fratura, conforme observamos na Figura 11.

Entretanto, notemos que estas definições somente são aceitáveis para o caso de carregamento "estático" e comportamento linear elástico perfeitamente plástico, pois uma estrutura não reflete as idealizações muitas vezes pretendidas pelo projetista, principalmente quanto à questão de considerar a sua ductilidade com base naquela apresentada pelo aço em ensaio de tração uniaxial. Portanto, nunca um ensaio deste tipo representa o comportamento real do aço na estrutura [6], pois estão envolvidas variáveis difíceis de serem controladas (ou 


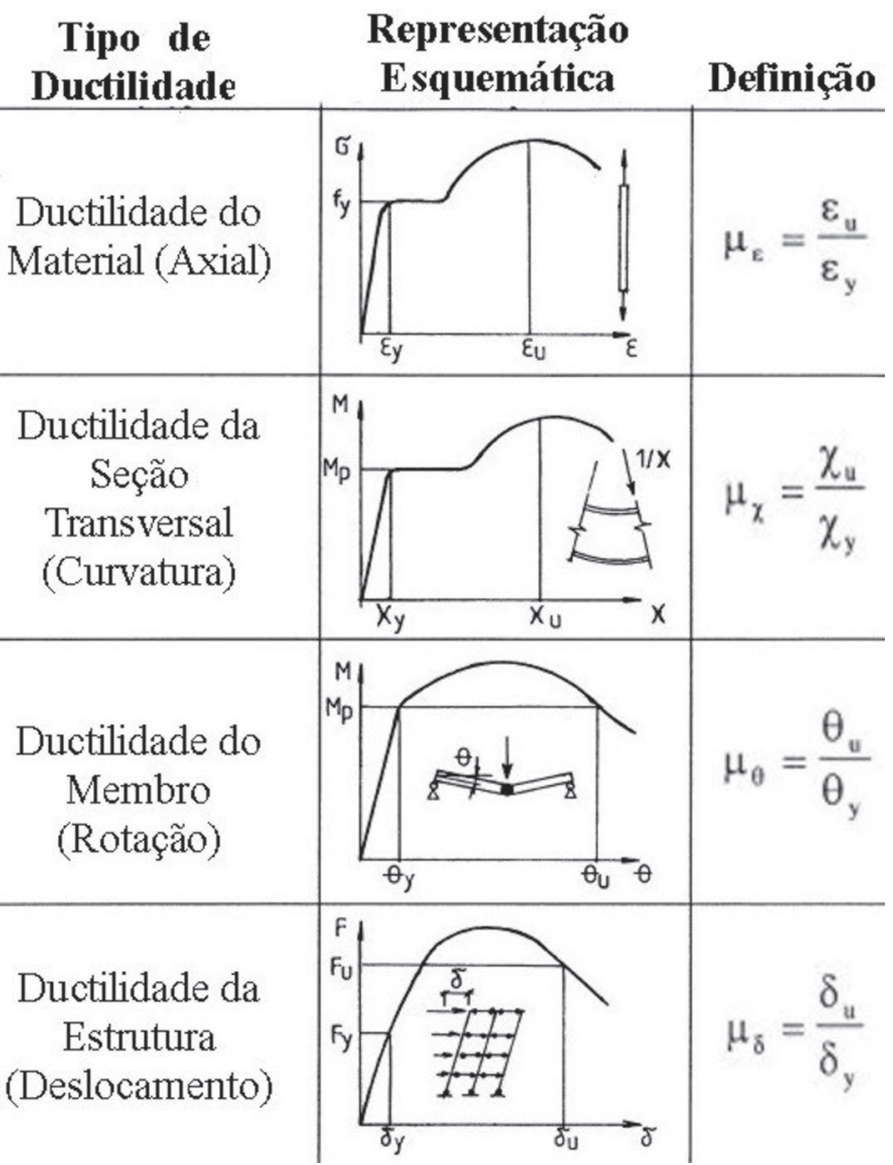

Figura 10 - Diversos "tipos" de ductilidade [6].
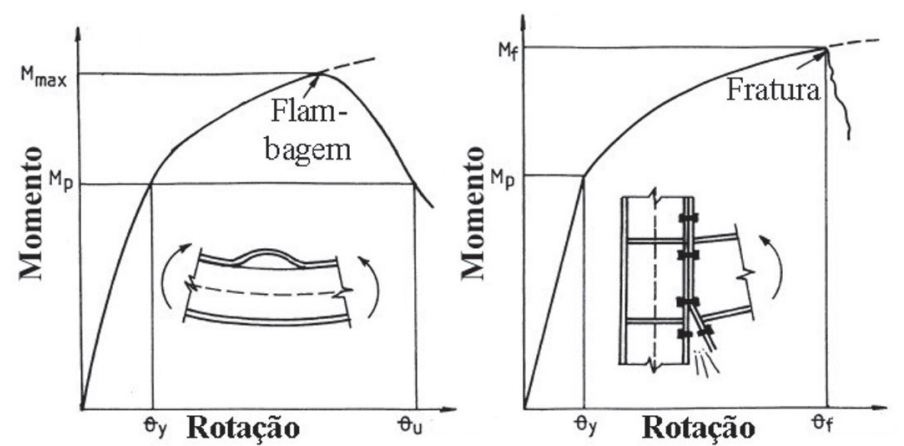

Figura 11 - Possíveis formas para colapso de um elemento [6].

incontroláveis), tal como limite de escoamento, temperatura, impacto, etc., conforme discutiremos mais adiante. Estes fatores provocam "erosão" (redução gradativa) das propriedades originais, ou "nativas" do aço, tal como mostramos na Figura 12. Entre a ductilidade do material e aquela que será disponível pela estrutura encontram-se, portanto, várias "ocorrências" de ordem mecânica e/ou metalúrgica, as quais são repartidas naquelas relativas aos elementos e às juntas [6]. Para os elementos: (a) relativa ao material, composta por classe do aço, razão $\mathrm{f}_{\mathrm{y}} / \mathrm{f}_{\mathrm{u}}$, aleatoriedade, taxa de deformação; (b) relativa à seção transversal, composta por tipo da seção, esbeltez da parede, interações da parede; (c) relativo aos membros, composta por endurecimento por deformação, flambagem, forças axiais e cargas cíclicas. Para as juntas: (a) relativa à junta do painel, composta pelo tipo da junta, mecanismo do cisalhamento e mecanismo do esmagamento; (b) relativa às mesas (flanges) da coluna, composta pelo tipo da coluna e ao mecanismo plástico; (c) relativa às conexões, composta pelo tipo da conexão, mecanismo plástico local, carregamento cíclico e taxa de deformação.

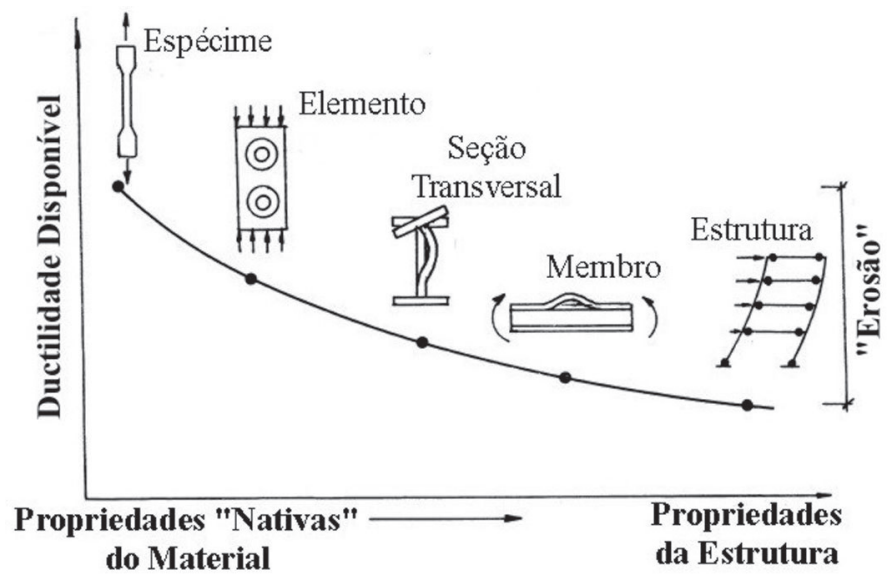

Figura 12 - Redução gradativa ("erosão") das propriedades nativas do aço [6].

Então, apesar dos aços estruturais apresentarem excelentes características, análises de falhas principalmente causadas por terremotos demonstraram, que em certas condições e essencialmente devido ao projeto estes aços e as suas juntas soldadas podem comportar-se de forma frágil. Por exemplo, até o ano de 1994 os engenheiros nos E. U. A. (mas não somente naquele país) projetavam as conexões soldadas entre coluna e viga resistentes a momento em pórticos, considerando-as entre os sistemas mais dúcteis do código de construção e virtualmente invulneráveis a terremotos... [17]. O conceito era de que estas conexões seriam capazes de se deformar plasticamente sem perda de resistência, através de rotações plásticas desenvolvidas no interior da viga. Lembramos que existem basicamente três ações às quais as conexões são submetidas, ou seja, força axial, força de cisalhamento e momento, com muitas conexões submetidas a mais de um tipo de ação simultaneamente, sendo elas usualmente denominadas de acordo com a ação predominante.

O "alarme" ecoou naquele ano, como consequência do terremoto Northridge que ocorreu naquele país, pois em grande número de edifícios estas conexões fraturaram de forma frágil, com relativamente pequeno dano arquitetônico associado [17]. Evidentemente aqueles engenheiros não esperavam tal comportamento, mas foi exatamente isto que ocorreu, conforme mostramos na Figura 13, com a fratura tipicamente (mas nem sempre) iniciando na junta com penetração completa, entre a mesa inferior da viga e a mesa da coluna. As trajetórias das fraturas variavam, por exemplo, entre somente no metal de solda; somente parte da mesa junto ao metal de solda; toda a seção transversal da coluna, etc. 


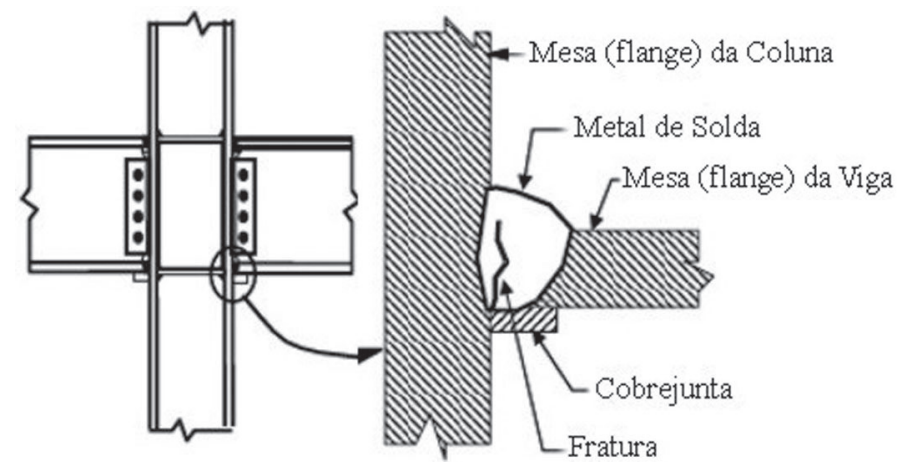

Figura 13 - Típicas juntas soldadas entre colunas e vigas de aço que falharam durante o terremoto Northridge nos E. U. A. [17].

Investigações demonstraram que diversos fatores concorreram para tornar as conexões soldadas inerentemente frágeis. Este caso é exemplar e se aplica a diversos tipos de estruturas; infelizmente, porém, por limitações de espaço não é possível apresentarmos detalhes das conclusões a que chegaram os membros da equipe altamente qualificada que o estudou [17], mas ressaltamos que: (a) a conexão entre a viga e a coluna é a parte menos resistente do conjunto; (b) a disposição da junta com a mesa inferior da viga é difícil de ser soldada e é grande a probabilidade da ocorrência de defeitos; (c) a configuração da junta soldada impossibilita verificação visual da raiz e é muito difícil para ensaios não destrutivos; (d) diferentemente do que indicavam modelagens típicas desta conexão, existe grande concentração de tensão na raiz da junta, que em conjunto com descontinuidades torna alta a probabilidade de trincas serem ali iniciadas; (e) para cordão de solda contínuo entre as mesas viga-coluna, é necessário furo de acesso na alma da viga e é severa a concentração de tensões neste local, com possível início de rasgamento dúctil das mesas da viga; (f) a região central na conexão entre as mesas da viga e da coluna é impedida de se deformar, particularmente quando seções espessas são empregadas, inibindo o desenvolvimento de escoamento neste local, resultando em altas tensões na junta soldada e amplificando a tendência ao início da fratura; (g) a prática de projeto empregada produzia relativamente fracas zonas de painel, resultando em ondulação das mesas da coluna adjacente à junta soldada e adicional aumento da tensão e deformação nesta região; (h) buscando reduzir custos, na metade de 1960 a indústria da construção começou a empregar eletrodo tubular autoprotegido, mas geralmente utilizando classe de eletrodo que inerentemente produzia metal de solda com baixa tenacidade e operando tipicamente com excessiva energia de soldagem; (i) como resultado, ocorriam fraturas frágeis iniciando em defeitos existentes nestas juntas, com o comportamento dúctil impedido de se manifestar; (j) naquela época as estruturas tendiam a ser altamente redundantes e quase toda junta viga-coluna era construída para comportar-se como parte do pórtico para resistir força lateral; $(\mathrm{k})$ estes membros eram de pequenas dimensões e (novamente, para reduzir os custos do trabalho) somente algumas vigas e colunas eram dimensionadas com partes maiores e suas conexões dirigidas à resistir momentos; (1) como a quantidade da deformação requerida nos elementos da conexão deste pórtico é relacionada com a razão comprimento/profundidade do membro, as suas dimensões foram aumentadas e as deformações requeridas nas conexões soldadas também aumentaram, fazendo estas conexões mais suscetíveis a comportamento frágil; (m) nos anos de 1960 e 1970 diversas pesquisas sobre pórticos de aço resistentes a momento foram realizadas com vigas usualmente fabricadas em aço ASTM A36 (36 ksi ou $\sim 250 \mathrm{MPa}$ de limite de escoamento); (n) entretanto, nos anos 1980 muitas usinas de aço adotaram processos de produção mais modernos, inclusive baseados em sucata e os aços assim produzidos tendiam a ser microligados apresentando maiores limites de escoamento; (o) desta forma, muitas corridas resultavam em aços com resistência similar ao Grau 50 (50 ksi ou $\sim 350 \mathrm{MPa}$ de limite de escoamento) e a junta soldada passava a ter resistência menor do que o conjunto, ou seja, alterava-se para "undermatching" [2].

Portanto, para a obtenção de comportamento dúctil confiável para pórticos resistentes a momento, foram necessárias alterações essenciais e complexas nas práticas de projeto, material, fabricação, ereção e qualidade assegurada, as quais na atualidade a indústria da construção dos E. U. A. e da Europa aparentemente realizaram com relativo sucesso. Provavelmente entre as mais importantes modificações de projeto, está tornar as juntas soldadas mais resistentes do que as vigas por elas conectadas, conforme veremos mais abaixo.

Uma série de fatores usualmente contribui para a redução da ductilidade local de estruturas de aço, por exemplo [7]: (a) o limite de escoamento real e aquele adotado no projeto são diferentes; (b) não é exatamente conhecida a resistência através da espessura do componente; (c) os ensaios de tenacidade dos metais base e de solda não são realistas; (d) a taxa de deformação não é considerada; (e) em conexões coluna/viga, os dados históricos das rotações plásticas necessárias foram subestimados; (f) a não verificação da possibilidade da ocorrência de estados de tensões tridimensionais em conexões soldadas de vigas altas; (g) a estimativa errada das distribuições de tensão nas extremidades das vigas; (h) deficientes projetos das conexões; (i) a não consideração da influência do carácter composto das vigas. Como consequência, atualmente há consenso de que a verificação da ductilidade da estrutura tem que ser quantificada no mesmo nível que resistência e rigidez.

Apesar de ser reconhecido que danos estruturais também ocorrem por deformações, a prática convencional do projeto de estruturas para cargas não sísmicas considera somente as demandas de resistência e rigidez. A verificação da resistência incluindo estabilidade é relacionada ao estado limite último, assegurando que o valor da força desenvolvida na estrutura permanece no intervalo elástico, ou algumas deformações plásticas podem ocorrer de acordo com premissas do projeto. Por sua vez, a verificação da rigidez é geralmente relacionada ao estado limite de serviço, com os deslocamentos da estrutura permanecendo dentro de limites aceitáveis.

Ainda assim, ductilidade continua a ser um parâmetro ambíguo e as normas ou Códigos pouco ajudam ao projetista na determinação de como empregar objetivamente os resultados dos ensaios existentes, tal como ocorre com resistência e rigidez [18, 19]. Para construções civis em aço, por exemplo, há exigência quanto as dimensões máximas de espessura dos metais base 
para determinados valores de energia absorvida no ensaio de impacto em diferentes temperaturas [20, por exemplo], sendo que este quesito também envolve a questão da probabilidade da ocorrência de decoesão lamelar —ou fratura por tensão ortogonal a planos de descontinuidades (silicatos, etc.) que porventura existam na espessura de chapas relativamente espessas e que não sofreram suficiente deformação (trituração) por laminação. Além disto, mínima ductilidade é requerida [13, por exemplo] e deve ser expressa em termos de limite de: (a) razão $\left(\mathrm{f}_{\mathrm{y}} / \mathrm{f}_{\mathrm{u}}\right) \leq(1 / 1,10)$, ou $\left(\mathrm{f}_{\mathrm{u}} / \mathrm{f}_{\mathrm{y}}\right) \geq 1,10$, onde $\mathrm{f}_{\mathrm{u}}$ é o especificado limite de resistência à tração e $\mathrm{f}_{\mathrm{y}} \mathrm{o}$ especificado mínimo limite de escoamento, pelas razões que explanamos; (b) alongamento na fratura não menor do que $15 \%$; (c) $\varepsilon_{\mathrm{u}} \geq 15 . \varepsilon_{\mathrm{y}}$, onde $\varepsilon_{\mathrm{u}}$ é a deformação correspondente $\mathrm{a} \mathrm{f}_{\mathrm{u}}$ e $\varepsilon_{\mathrm{y}}$ a deformação no escoamento $\left(\varepsilon_{\mathrm{y}}=\mathrm{f}_{\mathrm{y}} / \mathrm{E}\right)$. Também a AISC $[21]^{\mathrm{y}}$ especifica para a ductilidade em membros sujeitos a rótula plástica, entre outras exigências, que: (a) o especificado mínimo limite de escoamento não exceda $450 \mathrm{MPa}$; (b) a seção transversal daqueles em compressão seja duplamente simétrica, com relações definidas entre largura e espessura; (c) a resistência de projeto em compressão não deve exceder $\phi . \mathrm{f}_{\mathrm{y}} \cdot \mathrm{A}_{\mathrm{g}}$, onde $\phi$ é um fator usualmente menor do que 1 (neste caso 0,75 ) e $\mathrm{A}_{\mathrm{g}}$ a área bruta da seção transversal. Para sistemas resistentes a forças sísmicas, a AISC [21] especifica para membros dos quais se espera comportamento inelástico, que o mínimo limite de escoamento não exceda $345 \mathrm{MPa}-$ existem outros casos em que ele pode alcançar até $380 \mathrm{MPa}$ e em certos sistemas de colunas não deve exceder $450 \mathrm{MPa}$.

Portanto, enquanto as normas ou Códigos não oferecem soluções objetivas para a questão ductilidade, os projetistas e pesquisadores desenvolvem meios alternativos $[3,6,7,11,23$, 24].

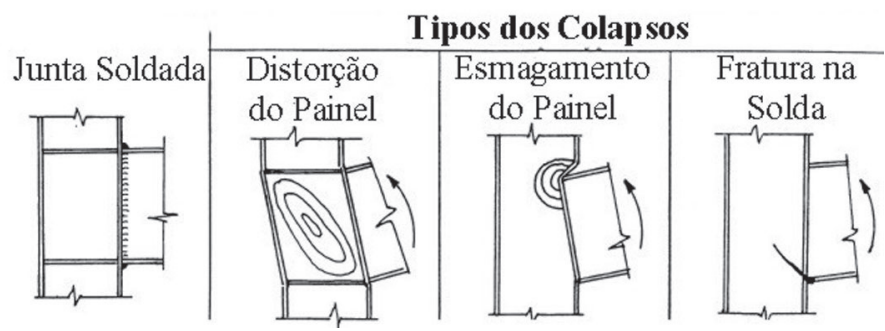

Figura 14 - Dependência da ductilidade em relação à importância do elemento na conexão [6].

A ductilidade de uma junta soldada depende da importância dos comportamentos de todos os componentes e entre a coluna e a viga da Figura 14, ela é dada pela deformação plástica em cisalhamento, pelo esmagamento do painel ou por fratura da solda [6]. Com base na experiência ganha através da análise de estruturas que sofreram danos por terremotos, verificou-se que a concentração do fenômeno inelástico nas juntas induz fratura frágil nas soldas e naquelas situações em que as soldas (e parafusos) não governam o comportamento, novas conexões têm sido propostas, todas baseadas na ideia de afastar a rótula plástica da intersecção coluna/viga. Existem várias soluções e, aparentemente, aquela que mostramos na Figura 15 é a mais efetiva $[3,7,23]$, sendo as larguras das mesas da viga reduzidas próximo da conexão (formato "dog-bone", ou "osso de cachorro") e neste local ocorre a rótula plástica, técnica que também permite vantajosamente reduzir as dimensões da coluna.

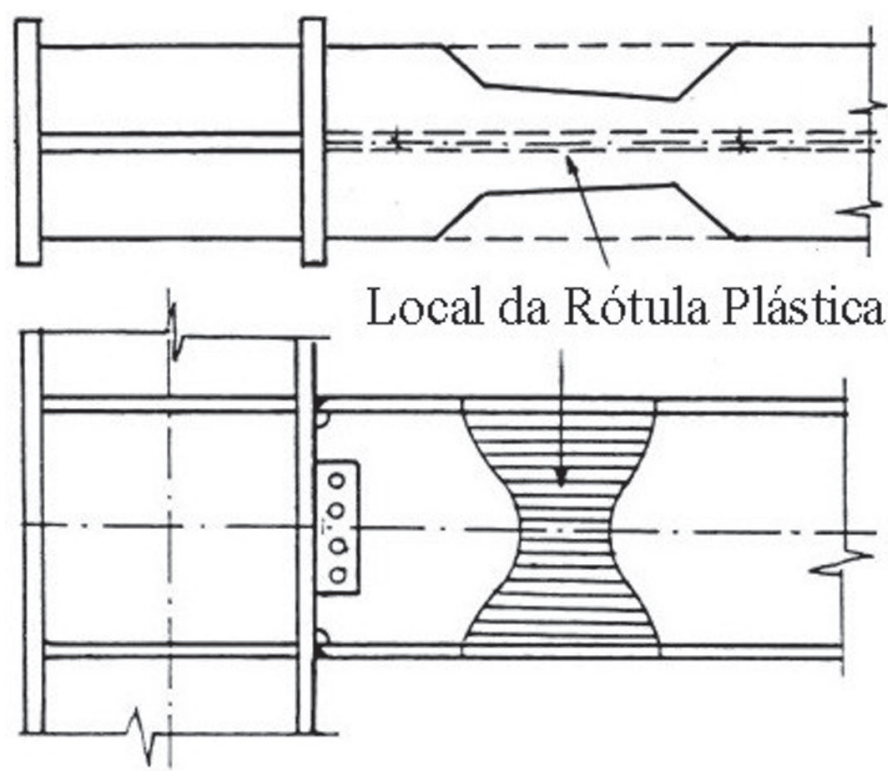

Figura 15 - Viga com região próxima à conexão em formato de "dog-bone" (osso de cachorro), como uma efetiva solução para deslocamento da rótula plástica [3].

Por sua vez, conforme mostramos na Figura 16, em juntas soldadas sujeitas a excentricidade "no plano" a solda está livre para se deformar em toda a sua extensão; entretanto, naquelas juntas em que há excentricidade "fora do plano", a parte da solda na zona de compressão não é livre para se deformar, pois existe apoio direto entre as chapas que estão soldadas. Esta diferença fundamental entre cargas excêntricas no plano e fora do plano, foi reconhecida [25] na derivação na formulação do estado limite último para a resistência de juntas soldadas excêntricas e tem sido adotada com diferentes níveis de conservadorismo por distintas normas e Códigos.

\section{Excentricidade}

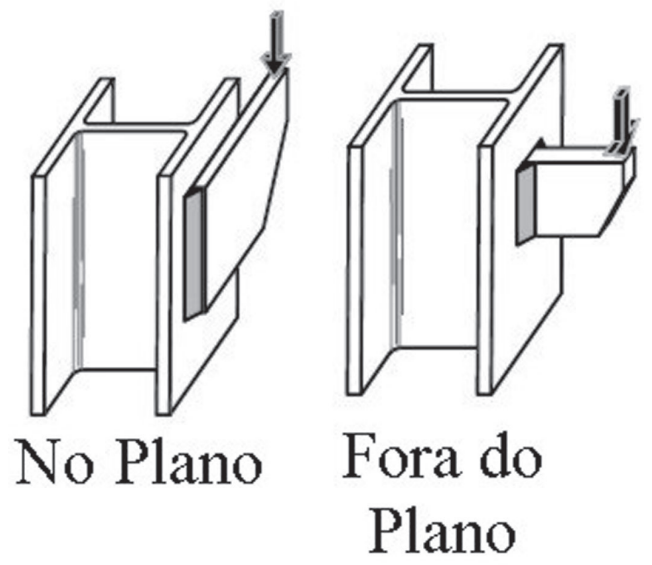

Figura 16 - Juntas soldadas com carregamento excêntrico. 
Outrossim, tal como mencionamos em artigo anterior [1], há diferença notável na resistência do metal de solda conforme é alterado o ângulo entre a direção da junta soldada e o carregamento — sendo a tensão admissível na solda transversal cerca de 50\% maior do que na longitudinal. Foram apresentadas equações [26-28] para consumíveis com resistência à tração $f_{\mathrm{s}}=60 \mathrm{ksi}(\sim$ $430 \mathrm{MPa}$ ); quase duas décadas após e empregando consumíveis com $\mathrm{f}_{\mathrm{s}}=70 \mathrm{ksi}(\sim 490 \mathrm{MPa})$, não somente foi corroborado este fato, mas também demonstrado [29] que a tensão suportada pela solda poderia ser cerca de 2,84 vezes maior do que aquela anteriormente encontrada e sendo proposta nova equação. Cerca de 15 anos após, este fato foi analisado em detalhes e confirmado [30]. Na Figura 17 estão razões entre as resistências de cordões de solda $\mathrm{F}_{\theta}$ em diferentes ângulos $\theta\left(0^{\circ}<\theta \leq 90^{\circ}\right)$ de aplicação da carga e a resistência do cordão de solda longitudinal $\left(\mathrm{F}_{0}\right.$, ou seja, $\theta=0^{\circ}$ ), quando relacionadas com as relações das razões entre deformações $(\Delta)$ e tamanho ("perna") do cordão de solda (z) de filete, sendo comparados dois trabalhos sobre o assunto $[26,29]$. Notemos que apesar das juntas transversais serem mais resistentes, elas se deformam muito menos e, portanto, possuem notavelmente menor ductilidade.

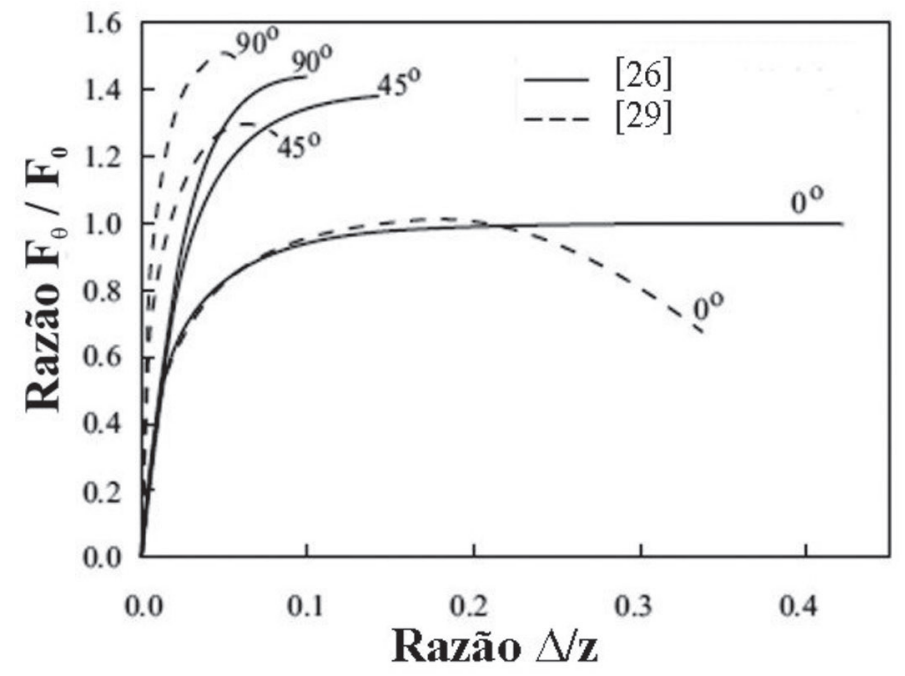

Figura 17 - Resistência da junta soldada em função do ângulo do carregamento e da deformação do cordão de solda [dados de 26 e 29].

\section{Conclusões}

Ao longo deste artigo procuramos demonstrar a necessidade, que tanto o(a) projetista, quanto o(a) engenheiro(a) de soldagem tem, de atentar para alguns importantes fatos relativos à ductilidade da junta soldada, notavelmente em certas situações ser ela inerentemente o local menos dúctil da estrutura. Além disto, projetos que redundam em excessiva rigidez têm que ser evitados e as conexões tratadas como parte integral da análise estrutural. Também tentamos enfatizar que não basta, de forma alguma, os metais base e de solda atenderem aos níveis de tenacidade (e/ou energia absorvida no ensaio de impacto) e ductilidade requeridos pelas normas e Códigos. Estes profissionais não podem somente se satisfazer com os resultados destes ensaios (na verdade, são guias gerais), pois enfaticamente repetimos, eles não representam adequadamente as situações reais pelas quais passam as mais diversas estruturas soldadas.

Então, um projeto satisfatório unicamente pode resultar, quando há visão da ductilidade como fruto de adequadas combinações dos metais base e de solda, dos componentes da estrutura e da estrutura de forma global.

Adicionalmente, analisamos brevemente aspectos matemáticos da ductilidade, na tentativa de mostrar que recursos aparentemente muito distintos são, na realidade, partes de um todo indivisível.

\section{Referências Bibliográficas}

[1] MACHADO, I. G. Dimensionamento de Juntas Soldadas de Filete: Uma Revisão Crítica. Soldagem \& Inspeção, 16(2): 189-201, Abr/Jun 2011. Nota: a versão impressa (ou digital em CD) deste artigo omitiu uma importante figura; está correta a versão disponível na página da ABS (www.abs-soldagem.org. $\underline{\mathrm{br} /})$.

[2] MACHADO, I. G. Novos Paradigmas para Especificação de Juntas Soldadas. Soldagem \& Inspeção, 17 (3): 278-288, Jul/Set 2012.

[3] PLUMIER, A. Behaviour of Connections. Journal of Constructional Steel Research, 29(1/3): 95-119, 1994.

[4] ENGELHARDT, M. D. Basic Concepts in Ductile Detailing of Steel Structures. "Webinar" desenvolvido como parte da "2007 North American Steel Construction Conference". American Institute of Steel Construction, 2007.

[5] PAUlAy, T. and PRIESTLEY, M. J. N. Seismic design of reinforced concrete and masonry buildings. John Wiley and Sons, USA, 1992.

[6] GIONCU, V. Framed structures. Ductility and seismic response. General Report. Journal of Constructional Steel Research, 55(1/3): 125-154, Jul 2000.

[7] PLUMIER, A. General report on local ductility. Journal of Constructional Steel Research, 55(1/3): 91-107, Jul 2000.

[8] BROEK, DAVID. Elementary Engineering Fracture Mechanics. Sijthoff \& Noordhoff, The Netherlands, 1978.

[9] VELESTOs A. and NEWMARK N. M. EFFECT of inelastic behaviour on response of simple system to earthquake motions. Proc. $2^{\text {nd }}$ World Conference on Earthquake Engineering, 855912, Tokio, Japan, 1960.

[10] POPOV, E. P. Development of U. S. codes. Journal of Constructional Research, 29(1/3): 191-207, 1994.

[11] HOUSNER, G. M. et al. Structural Control: Past, Present and Future. Journal of Engineering Mechanics, 123, (9): 897971, Sep 1997.

[12] Commentary and Worked Examples to EN 1993-1-10 "Material toughness and through thickness properties" and other toughness oriented rules in EN 1993. JRC-ECCS, 2008

[13] EN 1993-1-1: 2005. Eurocode 3: Design of steel structures - Part 1-1: General rules and rules for buildings.

[14] TIMOSHENKO, S. Strength of Materials, Vol. 2. Robert E. Krieger Publishing Company, $3^{\text {rd }}$ Ed., New York, 1976.

[15] KACHANOV, L. M. Fundamentals of the Theory of 
Plasticity. Dover Publications, Inc., 2004.

[16] PETERSON, R. E. Stress Concentration Factors. Joh Wiley \& Sons, New York, 1974.

[17] FEMA-355B. State of the Art Report on Welding and Inspection - SAC Joint Venture. USA, Sep 2000.

[18] TORABIAN, S., MIRGHADERI, S. R. and KESHAVARZI, F. Moment-connection between I-beam and built-up square column by a diagonal through plate. Journal of Constructional Steel Research, 70: 385-401, Mar 2012.

[19] CARBONELL-MÁRQUEZ, J. F., GIL-MARTÍN, L. M. and HERNÁNDEZ-MONTES, E. Strength design optimization of structural steel members according to Eurocode 3. Journal of Constructional Steel Research, 80: 213-223, Jan 2013.

[20] EN 1993-1-10: 2005. Eurocode 3: Design of steel structures - Part 1-10: Material toughness and through-thickness properties.

[21] ANSI/AISC 360-10. Specification for Structural Steel Buildings. American Institute of Steel Construction, 2010.

[22] ANSI/AISC 341-10. Seismic Provisions for Structural Steel Buildings. American Institute of Steel Construction, 2010.

[23] PLUMIER A. New design for safe structures in seismic zones. In: IABSE Symposium on Mixed Structures Including New Materials, Brussels, 1990. Citado por [7].

[24] PLUMIER, A. The Dogbone: Back to the Future. AISC Engineering Journal, 34(2): 61-67, 1997.

[25] DAWE, J. L. and KULAK, G. L. Welded Connections under Combined Shear and Moment. Journal of the Structural Division, ASCE, 100(ST4): 727-741, May 1972.

[26] BUTLER, L. J. and KULAK, G. L. Strength of fillet welds as a function of direction of load. Welding Journal, 50(5): 231s-234s, May 1971.

[27] BUTLER, L., PAL, J. S. and KULAK, G. L. Eccentrically Loaded Welded Connections. Journal of the Structural Division, ASCE (ST5), 98: 989-1005, May 1972.

[28] MIAZGA, G. S. and KENNEDY, D. J. L. Behavior of fillet welds as a function of the angle of loading. Canadian Journal of Civil Engineering, 16(4): 583-599, Aug 1989.

[29] LESIK, D. F. and KENNEDY, D. J. L. Ultimate strength of fillet welded connections loaded in plane. Canadian Journal of Civil Engineering, 17(1): 55-67, Feb 1990.

[30] CALLELE, L. J., GRONDIN, G. Y. and DRIVER, R. G. Strength and Behaviour of Multi-Orentation Fillet Weld Connections. Structural Engineering Report 225, Department of Civil and Environmental Engineering, University of Alberta, 2005. 